\title{
VIGOR OF SUNFLOWER AND SOYBEAN AGING SEED
}

Tatić, M. ${ }^{{ }^{*}}$, Balešević-Tubić, S. ${ }^{1}$, Đorđević, V. ${ }^{1}$,

Miklič, V. ${ }^{1}$, Vujaković, M. ${ }^{2}$, Đukić, V. ${ }^{1}$

${ }^{1}$ Institute of Field and Vegetable Crops, M. Gorkog 30, 21000 Novi Sad, Serbia

${ }^{2}$ Agricultural Extension Service Novi Sad, Temerinska 131, 21000 Novi Sad

Received: November 15, 2011 Accepted: December 10, 2011

\section{SUMMARY}

Seed aging and deterioration affect seed vigor and viability. The characteristics of the chemical composition of oil crops seed are related to specific processes occurring in the seed during storage. This study was performed to examine the changes in seed vigor of different sunflower and soybean genotypes under controlled and conventional (uncontrolled) conditions of natural aging for six and twelve months. Obtained results show that the degree of seed damage and the ability of seed to resist the negative effects of aging were influenced by duration and type of storage, as well as seed characteristics of the tested genotypes. The most valuable vigor test for both sunflower and soybean was cold test.

Key words: vigor tests, seed, storage, germination, sunflower, soybean

\section{INTRODUCTION}

Seed aging and viability are affected by a number of factors during storage, with air temperature and humidity being indisputably the most important ones of the external factors. The speed of seed aging process depends on the ability of seed to resist degrading changes, as well as on its protection mechanisms which are species-specific (Gupta and Aneja, 2004; Sismal and Delibas, 2004; Balešević-Tubić et al., 2005; Mohammadi et al., 2011). Due to its specific chemical composition, seed rich in lipids has limited viability. For example, sunflower seed storage demands special care due to high oil content which can easily provoke processes that can lead to loss of germination and viability. Fatty acid composition is the most important factor which determines oils susceptibility to oxidation (Morello et al., 2004). Seed quality parameters such as oil content, fatty acid composition and protein content are significantly influenced by storage conditions and duration (Ghasemnezhad and Honermeier, 2007).

Seed vigor can be viewed as a measure of accumulated damage in seed as viability declines. Vigor testing becomes more important in seeds stored under

* Corresponding author: e-mail: mladen.tatic@ifvcns.ns.ac.rs 
unknown or adverse storage conditions (Andrić et al., 2007; Mendes et al., 2009). Seed vigor testing is also used as an indicator of the storage potential of seed and proves to be a more reliable indicator than germination test (Balešević-Tubić et al., 2000; Tatić, 2007). There are many viability tests such as cold test, accelerated aging test, Hiltner test, etc. Since single tests fail to satisfy all demands, a few vigor tests should be used to assess seed viability. Cold test (Milošević and Malešević, 2004) provides data on seed viability even in very adverse germination conditions, which gives better insight into seed behavior during field emergence. Hiltner test imposes a physical stress on the seed, predicting seed emergence capacity under conditions of soil crust formation.

This research was conducted aiming at assessment of seed viability of plant species with high oil content (such as sunflower and soybean) after seed had been stored and aged for a certain period. Based on aged seed vigor assessment, we can establish its field emergence capacity and possibility of forming vigorous and healthy plants which will be high-yielding.

\section{MATERIALS AND METHODS}

Sunflower and soybean genotypes used in this research were developed at Institute of Field and Vegetable Crops, Novi Sad, Serbia. The seed was kept in two ways: 1 ) in a cool chamber (controlled conditions) at $4^{\circ} \mathrm{C}$ and relative humidity $80-85 \%$ and 2) under conventional storage conditions (uncontrolled conditions). Testing was performed after storage for 6 and 12 months.

\section{Standard laboratory test}

Four replicates $\times 100$ seed of each line were tested. Wet blotter paper (roll type) was used as germination medium for sunflower. Number of normal seedlings was estimated after a 10 -day incubation period at $25^{\circ} \mathrm{C}$ and relative humidity of $95 \%$. Moistened sterilized sand was used as germination medium for soybean. Number of normal seedlings was estimated after 9 days under the same condition as for sunflower.

\section{Hiltner test}

$4 \times 50$ seeds were placed onto moistened sand, and a $3 \mathrm{~cm}$ layer of cracked brick (previously sterilized and moistened) was placed upon them. Incubation period under optimal condition lasted for 10 days.

\section{Cold test}

$4 \times 50$ seeds were placed onto moistened soil (up to $40 \%$ of field capacity) at 5$8^{\circ} \mathrm{C}$ for seven days, and afterwards placed in a germination chamber at $25^{\circ} \mathrm{C}$ for four days. 
Germination (number of normal seedlings) was evaluated for both cold and Hiltner tests (ISTA, 2004). The results of the mentioned treatments were compared with fresh seeds germination (measured at the start of the experiment and used as the control treatment).

\section{Statistical analysis}

Mean comparison (t-test) was performed using statistical software Statistica 8 and relative values of differences between control and germination of stored seed were calculated for all vigor tests. Linear regressions between initial seed germination (control) and aged seed germination estimated by vigor tests were tested for slope significances, also using software Statistica 8.0. All values represented in this paper are average over four replications.

\section{RESULTS AND DISCUSSION}

Under the same storage conditions, seeds of various plant species lose viability to different extents. Negative effects of this process include decreased seedling emergence and decreased resistance to adverse germination conditions, ultimately resulting in yield loss. Storage mode and duration affects seed vigor, which can best be viewed from the relative values, i.e., difference between vigor of aged seed and control (Figure 1).
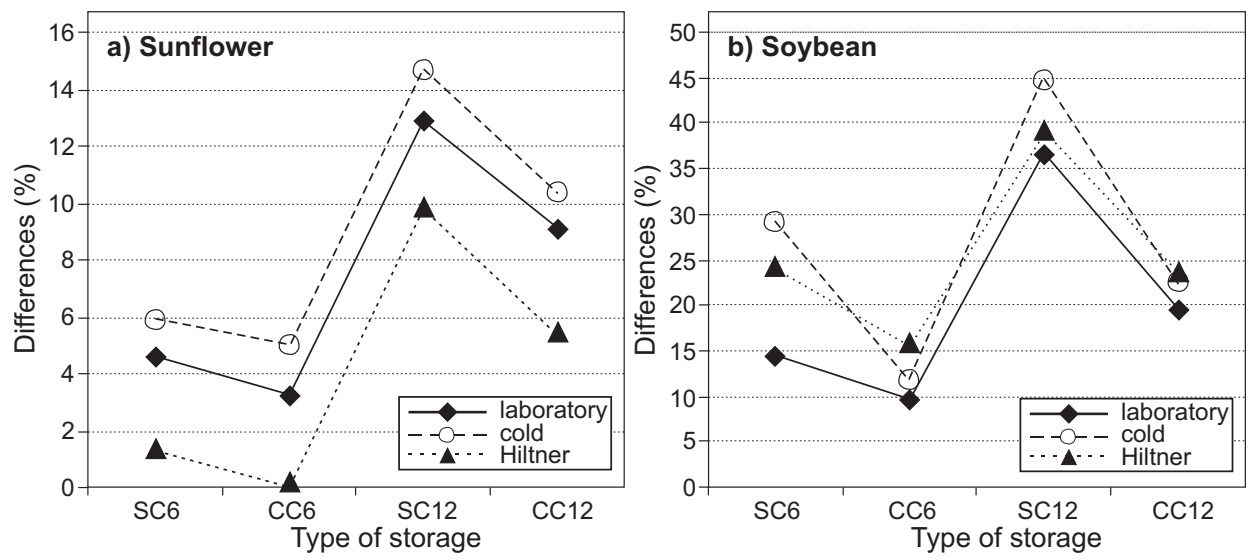

Figure 1: The difference between initial seed germination and seed germination under different storage types (SC-conventional conditions, $\mathrm{CC}$-controlled conditions, after 6 and 12 months)

Both tested plant species are known to express differences in seed vigor during storing as compared to the control, especially after 12 months under conventional storage conditions. The lowest difference was found in seed stored under controlled conditions for 6 months. Adverse storage conditions can provoke significant variations in seed viability (Tatić et al., 2008), and storage duration is negatively corre- 
lated with seed vigor (Šimić et al., 2007). Seed vigor declines first as seed deteriorates, followed by loss of germination and viability. The highest difference in vigor of aged seed and control in both plant species was found when cold test was applied. Due to stress caused by cold test low temperatures, the seed damaged during aging showed lowest vigor as compared to the control. Obtained results only confirm that a cold test is the most reliable test for assessing aged seed viability and seed reaction under field emergence conditions, as previously reported by Trawatha et al. (1995) and Balešević-Tubić et al. (2007a).

Regarding seed reactions to decreased vigor during storage, differences were found among certain genotypes (Table 1).

Table 1: Seed vigor of sunflower and soybean genotypes depending on duration and type of storage (SC-conventional conditions, CC-controlled conditions, after 6 and 12 months)

\begin{tabular}{|c|c|c|c|c|c|c|c|c|c|c|c|}
\hline \multirow{3}{*}{$\begin{array}{l}\text { Duration and } \\
\text { type of storage }\end{array}$} & \multicolumn{11}{|c|}{ Germination (\%) } \\
\hline & \multicolumn{5}{|c|}{ Sunflower genotypes } & \multicolumn{6}{|c|}{ Soybean genotypes } \\
\hline & Sf1 & Sf2 & $\mathrm{Sf3}$ & $\mathrm{Sf} 4$ & Sf5 & Sb1 & $\mathrm{Sb} 2$ & Sb3 & $\mathrm{Sb} 4$ & Sb5 & Sb6 \\
\hline \multicolumn{12}{|c|}{ a) Standard laboratory test } \\
\hline Control & 97 & 85 & 87 & 92 & 89 & 95 & 89 & 92 & 88 & 85 & 89 \\
\hline SC6 & 94 & 80 & 85 & 90 & 80 & 78 & 80 & 67 & 70 & 83 & 83 \\
\hline CC6 & 94 & 83 & 86 & 91 & 81 & 88 & 80 & 76 & 72 & 84 & 86 \\
\hline $\mathrm{SC} 12$ & 91 & 72 & 79 & 89 & 60 & 49 & 50 & 50 & 47 & 65 & 70 \\
\hline $\mathrm{CC} 12$ & 91 & 75 & 83 & 90 & 69 & 76 & 67 & 67 & 68 & 79 & 77 \\
\hline \multicolumn{12}{|c|}{ LSD $_{0.05}$ sunflower 4 ; soybean $\mathbf{7}$} \\
\hline \multicolumn{12}{|c|}{ b) Cold test } \\
\hline Control & 94 & 82 & 85 & 90 & 79 & 86 & 74 & 80 & 74 & 78 & 84 \\
\hline SC6 & 90 & 77 & 80 & 86 & 71 & 59 & 60 & 49 & 43 & 61 & 66 \\
\hline CC6 & 91 & 79 & 82 & 86 & 70 & 80 & 71 & 63 & 62 & 70 & 75 \\
\hline SC12 & 86 & 68 & 72 & 83 & 58 & 38 & 45 & 42 & 38 & 43 & 57 \\
\hline CC12 & 89 & 70 & 78 & 85 & 63 & 70 & 57 & 55 & 55 & 63 & 69 \\
\hline LSD $_{0.05}$ sunflow & soybe & an 8 & & & & & & & & & \\
\hline
\end{tabular}

LSD $_{0.05}$ sunflower 4; soybean 8

\begin{tabular}{|c|c|c|c|c|c|c|c|c|c|c|c|}
\hline & & & & & & & & & & & \\
\hline Control & 95 & 79 & 78 & 91 & 79 & 90 & 86 & 88 & 86 & 84 & 88 \\
\hline $\mathrm{SC} 6$ & 94 & 78 & 76 & 90 & 77 & 65 & 69 & 53 & 60 & 73 & 75 \\
\hline CC6 & 94 & 79 & 79 & 91 & 76 & 78 & 74 & 65 & 68 & 77 & 77 \\
\hline SC12 & 90 & 73 & 74 & 85 & 57 & 44 & 57 & 43 & 48 & 56 & 70 \\
\hline $\mathrm{CC} 12$ & 90 & 76 & 76 & 87 & 69 & 76 & 62 & 57 & 63 & 69 & 72 \\
\hline
\end{tabular}

LSD $_{0.05}$ sunflower 3; soybean 7

Sunflower genotypes:
Sf1-ocms-74
Sf2-cms-v-8931-3-4
Sf3-ocms-22
Sf4-ocms-98
Sf5-cms-ol-3

Sunflower genotypes:

Sf4-0cms-98

Sf5-cms-ol-3

\author{
Soybean genotypes: \\ Sb1-Afrodita \\ Sb2-Lasta \\ Sb3-Balkan \\ Sb4-Novosadjanka \\ Sb5-Vojvodjanka \\ Sb6-Morava
}


The largest variation in sunflower was found in genotype 5, and differences among genotypes were especially profound when cold test was applied to seed stored under conventional storage conditions. Soybean genotypes that stood out most were genotypes 1 and 3, but the differences in genotypes' reactions were significantly more profound as compared to the tested sunflower genotypes. Genetic factors and seed chemical composition influence the expression of seed deterioration and vigor decline (Balešević-Tubić, 2001; Malenčić et al., 2003). One must be always keep in mind that seed is a living organism in which many biological processes take place that can damage the seed and reduce its quality, especially in case of oily seeds, where the genotypes specificity is important (Balešević-Tubić et al., 2010).

Considering initial seed germination of sunflower genotypes (control) and seed germination after a certain storage period, a high correlation was found both in standard laboratory germination and in cold test. Obtained high correlation, especially when cold test was applied (from $\mathrm{R}^{2}=0,92$ to $\mathrm{R}^{2}=0,98$ ), shows that the initial sunflower seed germination can be taken as one of the most important factors of storage duration and seed damage degree (Figure 2).

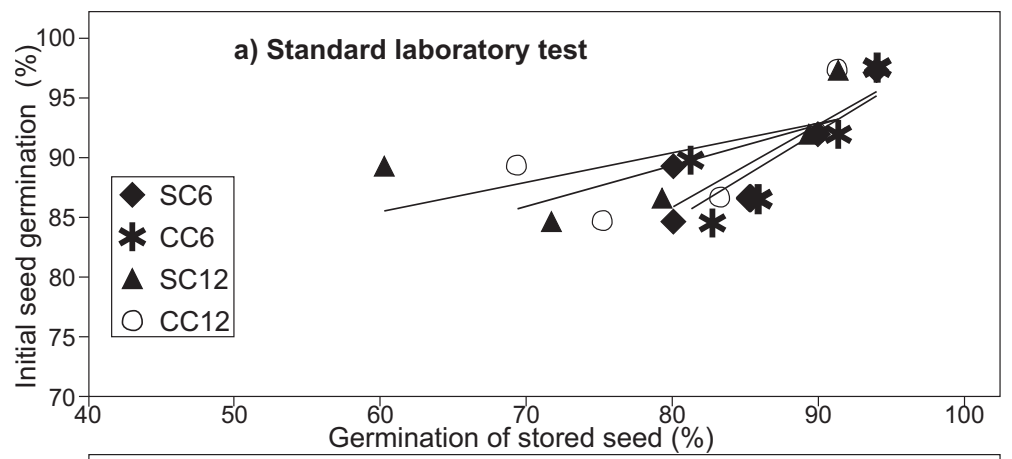

$$
\begin{gathered}
\text { SC6 } \\
y=0.6884 x+30.885 \\
R^{2}=0.7385 \\
\text { CC6 }
\end{gathered}
$$$$
y=0.7541 x+24.344
$$$$
\mathrm{R}^{2}=0.6958
$$

$\mathrm{SC} 12$

$y=0.245 x+70.792$

CC12

$y=0.3467 x+61.619$

$R^{2}=0.4396$

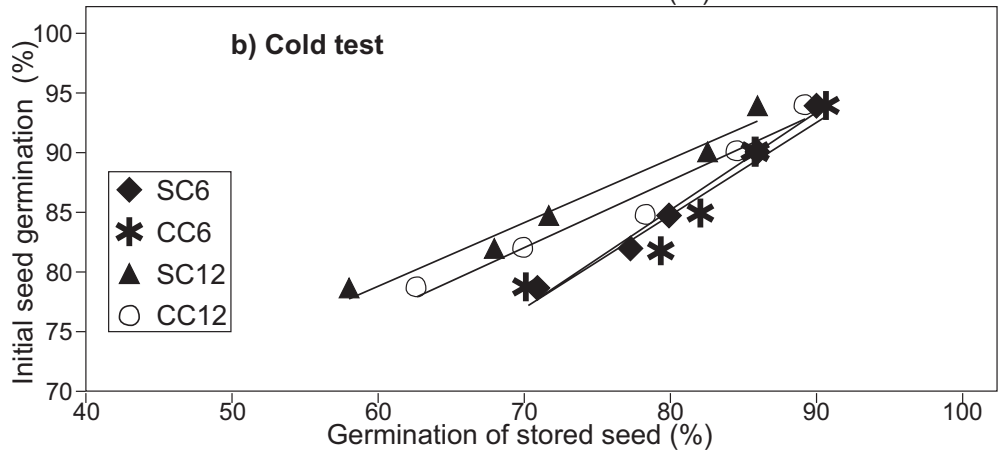

SC 6

$y=0.8225 x+19.353$

$R^{2}=0.9842$

CC6

$y=0.7791 x+22.292$ $\mathrm{R}^{2}=0.9256$

$\mathrm{SC} 12$

$y=0.5344 x+46.711$

$R^{2}=0.969$

CC12

$y=0.558 x+42.898$

$R^{2}=0.9604$

Figure 2: Correlation between stored seed germination and initial seed germination of sunflower genotypes estimated by vigor tests (SC-conventional conditions, CCcontrolled conditions, after 6 and 12 months) 
High vigor seeds are expected to tolerate high temperature and humidity and retain their capability to produce normal seedlings (Balešević-Tubić, 2001). Soybean genotypes (Figure 3) showed correlation between initial germination and germination after storage only when cold test was applied, and this correlation was much lower than in sunflower genotypes. The highest correlation was in seed stored under controlled conditions $\left(\mathrm{R}^{2}=0,50 ; \mathrm{R}^{2}=0,68\right)$, indicating that soybean genotypes can utilize initial germination as a factor of seed storage duration only under mild stress conditions. Under high stress of conventional storage conditions, initial seed germination of soybean genotypes is not as important for its viability, presuming that other factors also strongly affect processes within stored seed. Seed vigor is clearly related to many other components of physiological seed quality, as well as production and storage conditions (Walters, 1998; Bailly et al., 2002; Nasreen and Khan, 2002; Sisman, 2005).

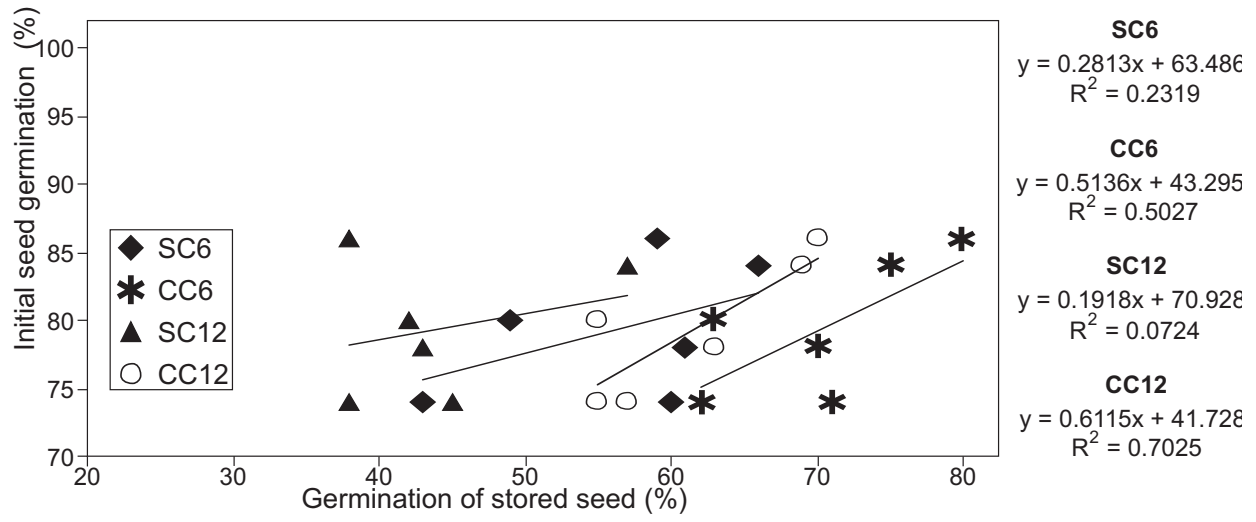

Figure 3: Correlation between stored seed germination and initial seed germination of soybean genotypes estimated by cold test (SC-conventional conditions, CC-controlled conditions, after 6 and 12 months)

\section{CONCLUSIONS}

Seed storage includes seed protection and preservation. Stored seed damage is not often manifested as significant germination loss, but as seed viability and vigor loss.

Vigor testing is more important for stored seed, especially under conventional (uncontrolled) storage conditions. Cold test was the best indicator of aged seed damage, which was most profound after 12 months under conventional storage conditions both in sunflower and soybean genotypes. Differences in genotypes' sensitivity to storage conditions and duration were evident, especially in soybean which was more sensitive than sunflower. According to very significant dependence of initial sunflower seed germination and seed germination after a certain storage period, 
it can be said that initial sunflower seed germination can be used as a reliable factor when deciding on storage duration. However, soybean genotypes showed substantial effects of other factors, thus the initial seed germination must be considered with care, especially under uncontrolled storage conditions.

\section{REFERENCES}

Andrić, L., Teklić, T., Vratarić, M., Sudarić, A., Duvnjak, V., 2007. Soybean seed vigour and field emergence under influence of cultivar, seed age and planting date. Cereal Research Communication 35(2): 177-180.

Bailly, C., Bogatek-Leszczynska, R., Come, D., Corbineau, F., 2002. Changes in activities of antioxidant enzymes and lypoxigenase during growth of sunflower seedlings from seeds of different vigour. Seed Science Research 12: 47-55.

Balešević-Tubić, S., Milošević, M., Vujaković, M., Zlokolica, M., Nikolić, Z., 2000. Starenje semena (Seed ageing). Proceedings of the Institute of Field and Vegetable Crops 33: 207212.

Balešević-Tubić, S., 2001. Uticaj procesa starenja na životnu sposobnost i biohemijske promene semena suncokreta (The influence og aging process on seed viability and biochemical changes in sunflower seed). (Ph.D.)T hesis-University of Novi Sad, Novi Sad.

Balešević-Tubić, S., Malenčić, Đ., Tatić, M. and Miladinović, J., 2005. Influence of aging process on biochemical changes in sunflower seed. Helia 28(42): 107-114.

Balešević-Tubić, S., Tatić, M., Miladinović, J., Pucarević, M., 2007a. Changes of faty acids content and vigour of sunflower seed during natural aging. Helia 30(47): 61-67.

Balešević-Tubić, S., Tatić, M., Hrustić, M., Miladinović, J., Maksimović, L., 2007b. The influence of aging process on germination and seedling growth of sunflower seed. Proceedings The First Joint PSU-UNS International Conference on BioScience: Food, Agriculture and the Environment, Thailand: 198-202.

Balešević-Tubić, S., Tatić, M., Đorđević, V., Nikolić, Z., Đukić, V., 2010. Seed viability of oil crops depending on storage conditions. Helia 33(52): 153-160.

Ghasemnezhad, A., Honermeier, B., 2007. Influence of storage conditions on quality and viability of high and low oleic sunflower seeds. International Journal of Plant Production 3(4): 41-50.

Gupta, A., Aneja, K.R., 2004. Seed deterioration in soybean varieties during storage-physiological attributes. Seed Research 32: 26-32.

ISTA, 2004. International Rules for Seed Testing. International Seed Testing Association, Switzerland.

Malenčić, Đ., Popović, M. and Miladinović, J., 2003. Stress tolerance parameters in different genotypes of soybean. Biology Plantarum 46: 141-143.

Mendes, C.R., de Moraes, D.M., 2009. Respiratory activity for the differentiation of vigor on soybean seed lots. Revista Brasileira de Sementes 31(2): 171-176.

Milošević, M., Malešević, M., 2004. Semenarstvo (Seed science). Institute of Field and Vegetable Crops, Novi Sad. Pp. 110-114.

Mohammadi, H., Soltani, A., Sadeghipour, H.R., Zeinali, E., 2011. Effect of seed aging on subsequent seed reserve utilization and seedling growth in soybean. International Journal of Plant Production 5(1): 65-70.

Morello, J.R., Motilva, M.J., Tovar, M.J., Romero, M.P., 2004. Changes in commercial virgin olive oil (CV Arbequina) during storage with special emphasis on the phenolic fraction. Journal of Food Chemistry 85: 357-364.

Nasreen, S., Khan, M.Y., 2002. Time-course study of seed viability and vigor in sunflower inbred lines under ambient storage condition. Asian Journal of Plant Sciences 1(2): 169-170.

Sisman, C., Delibas, L., 2004. Storing sunflower seed and quality losses during storage. Journal of Central European Agriculture 4: 239-250.

Sisman, C., 2005. Quality losses in temporary sunflower stores and influences of storage conditions on quality losses during storage. Journal of Central European Agriculture 6: 143-150.

Šimić, B., Sudarić, A., Liović, I., Rozman, V., Ćosić, J., 2007. Influence of storage condition on seed quality of maize, soybean and sunflover. Agriculturae Conspectus Scientificus 72(3): 211-213. 
Tatić, M., 2007. Uticaj endogenih i egyogenih činilaca na proces starenja i životnu sposobnost semena soje [Glycine max. (L.) Merr.] (Effect of endogenous and egzogenous factors on aging process and soybean seed viability [Glycine max. (L.) Merr.]). (Ph.D.)ThesisUniversity of Novi Sad, Novi Sad.

Tatić, M., Balešević-Tubić, S., Vujaković, M., Nikolić, Z., 2008. Changes of germination during natural and ascelerated aging of soybean seed. Proceedings The Second PSU-UNS International Conference on BioScience: Food, Agriculture and Environment, Serbia. Pp. 256-259.

Walters, C., 1998. Understanding the mechanisms and kinetics of seed aging. Seed Science Research 8: 223-244. 